\title{
Loneliness in Pre and Post-operative Cancer Patients A Mini Review
}

\author{
Ami Rokach a, b* \\ ${ }^{a}$ Ph. D, Psychology Department, York University, Canada \\ ${ }^{b}$ The Centre for Academic Studies, Israel
}

\begin{abstract}
This review explored the experience of hospitalization and the experience of cancer patients who were undergoing Ear Nose and Throat [ENT] surgery. Hospitals, which were designed with treatment and healing in mind, are known to be the source of uncontrollable noise, physicians who talk in a language that patients do not understand. Entering the hospital as a patient, one becomes part of that very complex system, which may include being treated as a 'nonperson,' not getting enough information, and losing control of daily activities. Hospitalized patients' social contact is limited to interaction with the medical staff which thus become a key factor in determining the quality of care, and whether the patients can successfully cope with the stress of their hospitalization experience.

Loneliness was found to be associated with a range of negative physical health outcomes such as dementia, increased blood pressure, suicidal thinking and unhealthy and damaging behaviors such as smoking, excess alcohol consumption and lack of exercise leading and contributing to increased mortality. Being, both, hospitalized and in the midst of a frightening illness they experience loneliness and isolation.
\end{abstract}

\section{Keywords:}

Loneliness;

Hospitalization;

Malignancy;

Post-Surgery.

\section{Article History:}

Received: 13 November 2018

Accepted: 11 January 2019

\section{1- Introduction}

Hospitalization happens to most people at some point in their lives. Surgery, which is commonly feared by most, may be part of that experience [1]. We often think of the hospital as a safe and healing environment designed to help treat people inflicted with a variety of illnesses. Patients, we know, receive the most contemporary care available, benefiting from modern technology in the hands of professional and dedicated doctors and staff with most updated treatment available [2]. And yet illness and hospitalization exert a great deal of psychological distress. It is said to be one of the most distressful events people might actually experience in their life time [3].

Illness, with its various symptoms, creates a major stressor on one's life [4]. Surgery may result in pain, fatigue, and, in more severe cases, immobility and even loss of bodily functions and control which often put the body into a state of continuous stress [5]. Following surgery, the patient may evidence the uncontrollable and unpredictable nature of his condition, the state of apprehension and even perceived threat to one's life when the diagnosis is of cancer related surgery. That may have a considerable effect on the patient's thoughts, emotions, and behaviors [6-8].

The modern hospital has been conceived as a having morphed from a prison for the contagious into a sterilized concrete incubator, which aims to keeping patients warm and under control, and provides them with a healing environment. All its components - doctors, nurses and bureaucrats - work together to provide patients with what is seen to be needed for them to heal. However, in addition to that, we must remember that with the exception of the limited visiting time of their family and friends, hospitalized patients' social contact is limited to interaction with the medical staff which thus become a key factor in determining the quality of care, and whether the patients can successfully cope

\footnotetext{
* CONTACT: Arokach@yorku.ca

DOI: http://dx.doi.org/10.28991/esj-2019-01168
}

(C) This is an open access article under the CC-BY license (https://creativecommons.org/licenses/by/4.0/). 
with the stress of their hospitalization experience [9-11]. By definition, this interaction is imbalanced; the patients are quite powerless, often passive, weak and in pain and due to their illness are dependent on the medical staff- physicians, nurses, and supporting staff - which are in complete control of the patient's daily life. Those medical people are endowed with the knowledge, authority and power, and are consequently so very influential on the patient while he or she is hospitalized $[8,12]$.

Surgery, which some people undergo, includes multiple stressful concerns about one's physical condition, painful procedures and post-operative pain, worries about survival and recovery, and separation from family and friends while the person recovers, is in isolation, or is not allowed to have visitors. Research indicated that even surgeries that may be considered "minor" may evoke strong psychological reactions in patients [13]. It was found that during the waiting period for surgery and even more so following one, the patient's world undergoes a great 'reduction' in scope and his psychological world become egocentric [14]. Surgery evokes fears such as anxiety due to anticipated pain and physical discomfort, and sometimes fears about having a serious and life-threatening illness or dying $[14,15]$.

Hospitals, which were designed with treatment and healing in mind, are known to be the source of uncontrollable noise [16]. It was compared to the loudness of heavy traffic which can damage one's hearing after just eight hours of exposure [17]. That noise not only disturbs patients' sleep, but especially for post op patients whose sensitivity to pain is increased, it may contribute to increased requests for pain medication $[3,18]$. Following surgery, and while struggling with the effects of anesthesia, pain and healing, with the exception of friends almost everyone around the patient is in a position of superior knowledge and power. That may add to the patient's stress and may enhance the pain that he attempts to cope with [3]. While physicians care about their patients we can commonly see in hospitals depersonalization, where patients are seen as if they are broken machines needing to be fixed without the medical staff needing to pay much heed to their emotional and psychological needs which are closely related to post surgery healing. As was repeatedly demonstrated stress adds to reduce the body's immune functioning and thus delays the healing of wounds, it heightens pain and increases the possibility of post-operative infections [13].

Research demonstrated that the greater the stress and anxiety pre-operatively, the slower and more complicated the post-operative recovery [19]. And inversely, when anxiety is low, social support high, and positive outlook is high before surgery, there are positive physical and psychological effects post surgically [20]. "There is certainly ample evidence that social support can moderate the effects of psychological stress; in addition, a number of studies have shown relationships between social support and dimensions of autonomic, endocrine, and immune function, with family ties appearing to be a key source of support related to physiological functioning" [13].

\section{2- Loneliness}

Loneliness is prevalent and common which recent estimates suggest that it is experienced by up to $32 \%$ of adults $[11,21]$. Being social creatures, humans' quality of life is intimately intertwined with social intercourse. Consequently, social disconnection negatively affects our psychological, physiological and even spiritual well-being [22]. Social connection is good and important to our health, but it is not just relationships that we are after, as we also need mutual concern and caring for those relationships to be satisfactory [23, 24].

Loneliness transcends age, gender, race, marital or socio-economic status and it may be both persistent and continuous or short lived [25, 26, 8]. The correlates of loneliness include sadness and depression (Boothet al., 1992; Hawkley et al, 2010) as well as low life satisfaction (Riggio et al., 1993) [27-29]. Hostility, alcoholism, poor selfconcept, and psychosomatic illnesses were also linked to loneliness [26]. Loneliness can severely compromise the quality of life of people, especially of the ill. Loneliness was found to be associated with a range of negative physical health outcomes (Shankar et al, 2011) such as dementia (Wilson et al 2007; Shankar et al, 2011), increased blood pressure (Hawkley et al, 2010), suicidal thinking (Fässberg et al., 2014) and unhealthy and damaging behaviors such as smoking, excess alcohol consumption and lack of exercise leading and contributing to increased mortality (Shankar et al, 2011) [28, 30-32]. Research indicates that psychological factors are clinically significant and are correlated with immune-related health outcomes, including infectious diseases, cancer, autoimmune diseases, and HIV, as well postoperative healing and pain [33, 34].

Entering the hospital as a patient, one becomes part of that very complex system, which may include being treated as a 'nonperson,' not getting enough information, and losing control of daily activities [35]. It is common for the hospitalized to become identified by their illness. It is not uncommon to hear a physician telling the nurse to 'attend to the multiple fractures in room...'. Patients' identities, comments and questions, and emotional needs are often ignored by the hospital staff [36]. Rokach and Brock $(1997,1998)$ found consistent differences in the reported experiences of loneliness between North American men and women [37, 38]. Women's socialization in the Western world prepares them more than men to engage in self-reflection, expressing their emotions, and being tuned into what they feel and how 
they act $[39,40]$. Cancer patients may experience difficulties in interpersonal relationships due to the various constraints and restrictions imposed by their illness. As they experience a decreased ability to cope with the disease, the quality of their social interactions also decreases [41, 42]. Patients afflicted with cancer describe feeling helpless, hopeless, and they typically lack the social and emotional support that they so desperately need, which may contribute to a decreased knowledge that they can address the situation, and that often results in feelings of loneliness and alienation [8, 43].

Rokach and Brock (1997) developed a scale, not to measure the intensity of loneliness, but to explore the qualitative dimensions of loneliness. Briefly, it includes five dimensions. Emotional distress, which captures the pain, suffering and turmoil of loneliness can be predicted by the sense of coherence and sex [37]. Women, which are socialized to express their feelings more than men do may report higher rates of emotional distress, but not actually differ from men in how they experience loneliness and pre and post-operative issues [44]. The second dimension of loneliness is Social inadequacy and alienation which addresses one's social inadequacy, unsuccessful and consequently engagement in selfgenerated social detachment that are part of the loneliness experience [45].

Growth and discovery, the third of Rokach and Brock's loneliness dimensions, captured the growth-enhancing and enriching aspects of loneliness and the increased feelings of inner strength and self-reliance that follow. It is expected that people afflicted with cancer, and are just before or after surgery, would not score highly on this dimension, as their entire being is geared towards survival and coping with the looming threat, rather than be concerned about personal growth. Interpersonal isolation has been recognized as significantly affecting poor health so much as that its negative effects were compared to cigarette smoking, high blood pressure, obesity, and sedentary lifestyle [35, 46, 47]. As can be intuitively expected, when one does not feel secure in his ability to understand, predict and in some way control his environment and body, one may experience an enhanced feeling of isolation and alienation. Self-alienation, the last of the five factors which comprise the experience of loneliness, describes a numbness, a detachment from one's self possibly leading to immobilization. It may be expected, intuitively, that when one is unsure of his world as the situation may be when hospitalized and undergoing surgery, one would be susceptible to experience numbness and selfdetachment. Illness may be a crisis for the ill person, a time of fear and loneliness. Serious Illness such as cancer may cause a redefinition of one's identity, and the relationship between the person and himself may also be affected [42, 48].

In conclusion, Serious illness, surgery and the process of hospitalization- in addition to uncertainty and anxiety and those often negatively and significantly affect their pain level, discomfort, and healing. It behooves us, as a society and especially those entrusted with healing people, to address those emotional issues, just as the medical needs are dealt with. Although there are mental health professionals in hospitals, the mission of the establishment is to look after the physical ailments of patient and attend to their pain and illness. Research that was reviewed in this article clearly demonstrates he need to attend to patients' emotional, cognitive and spiritual needs.

\section{3- Conflict of Interest}

The authors declare no conflict of interest.

\section{4- Ethical Approval}

This work did not involve the use of animals and therefore ethical approval was not necessarily required.

\section{5- References}

[1] Covinsky, Kenneth E., Robert M. Palmer, Richard H. Fortinsky, Steven R. Counsell, Anita L. Stewart, Denise Kresevic, Christopher J. Burant, and C. Seth Landefeld. "Loss of Independence in Activities of Daily Living in Older Adults Hospitalized with Medical Illnesses: Increased Vulnerability with Age.” Journal of the American Geriatrics Society 51, no. 4 (April 2003): 451-458. doi:10.1046/j.1532-5415.2003.51152.x.

[2] Rollins, Judy A. "Evidence-based hospital design improves health care outcomes for patients, families, and staff." Pediatric nursing 30, no. 4 (2004): 338-340.

[3] Hughes, Brian M. "Psychology, Hospitalization and Some Thoughts on Medical Training." European Journal of Psychotherapy \& Counselling 4, no. 1 (April 2, 2001): 7-26. doi:10.1080/13642530110040109.

[4] Sellick, Scott M., and Alan D. Edwardson. "Screening New Cancer Patients for Psychological Distress Using the Hospital Anxiety and Depression Scale.” Psycho-Oncology 16, no. 6 (2007): 534-542. doi:10.1002/pon.1085.

[5] Meredeth A. Rowe "The Impact of Internal and External Resources on Functional Outcomes in Chronic Illness." Research in Nursing \& Health 19, no. 6 (1996): 485- 497. doi:10.1002/(sici)1098-240x(199612)19:6<485::aid-nur4>3.0.co;2-k.

[6] Mishel, Merle H. “Uncertainty in Chronic Illness.” Annual Review of Nursing Research 17, no. 1 (January 1999): $269-294$. doi:10.1891/0739-6686.17.1.269. 
[7] Raps, Charles S., Christopher Peterson, Maritza Jonas, and Martin E. Seligman. "Patient Behavior in Hospitals: Helplessness, Reactance, or Both?" Journal of Personality and Social Psychology 42, no. 6 (1982): 1036-1041. doi:10.1037/00223514.42.6.1036.

[8] Rokach, Ami, and AMi ShA'kEd. Together and lonely: Loneliness in intimate relationships-Causes and coping. Nova Science Publishers, 2013.

[9] Attree, Moira. "Patients' and relatives' experiences and perspectives of 'Good' and 'Not so Good' quality care" Journal of Advanced Nursing 33, no. 4 (2001): 456-466. doi:10.1046/j.1365-2648.2001.01689.x.

[10] Thomas, L. H. and Bond, S. "Measuring patients' satisfaction with nursing: 1990-1994.” Journal of Advanced Nursing 23, (1996): 747-756. doi:10.1111/j.1365-2648.1996.tb00047.x.

[11] Cacioppo, John T., Louise C. Hawkley, and Ronald A. Thisted. "Perceived Social Isolation Makes Me Sad: 5-Year Cross-Lagged Analyses of Loneliness and Depressive Symptomatology in the Chicago Health, Aging, and Social Relations Study.” Psychology and Aging 25, no. 2 (2010): 453-463. doi:10.1037/a0017216.

[12] Schröder, Kerstin EE, and Ralf Schwarzer. "Do partners' personality resources add to the prediction of patients' coping and quality of life?." Psychology and health 16, no. 2 (2001): 139-159. doi:10.1080/08870440108405496.

[13] Kiecolt-Glaser, Janice K., Gayle G. Page, Phillip T. Marucha, Robert C. MacCallum, and Ronald Glaser. "Psychological influences on surgical recovery: perspectives from psychoneuroimmunology." American Psychologist 53, no. 11 (1998): 1209.

[14] Rokach, B. \& Rokach, A. Medicine, radiology, hospitalization, and loneliness. In A. Rokach, [Editor] Loneliness updated: "Recent research on loneliness and how it affects our life" (2013): 270-283, Abingdon, UK: Routledge.

[15] Montgomery, Guy H., and Dana H. Bovbjerg. "Presurgery distress and specific response expectancies predict postsurgery outcomes in surgery patients confronting breast cancer." Health Psychology 23, no. 4 (2004): 381.

[16] Holmberg, Sharon K., and Sharon Coon. “Ambient Sound Levels in a State Psychiatric Hospital.” Archives of Psychiatric Nursing 13, no. 3 (June 1999): 117-126. doi:10.1016/s0883-9417(99)80042-9.

[17] Atkinson, Rita L., Richard C. Atkinson, Edward E. Smith, and Daryl J. Bem. Introduction to psychology. Harcourt Brace Jovanovich, 1990.

[18] Topf, Margaret. "Effects of Personal Control over Hospital Noise on Sleep.” Research in Nursing \& Health 15, no. 1 (February 1992): 19-28. doi:10.1002/nur.4770150105.

[19] Johnston, Marie Ed, and Louise Ed Wallace. Stress and medical procedures. Oxford University Press, 1990.

[20] Contrada, R. J., E. A. Leventhal, and J. R. Anderson. "Psychological preparation for surgery: Marshaling individual and social resources to optimize self-regulation." International review of health psychology 3 (1994): 219-266.

[21] Cacioppo, John T., and William Patrick. Loneliness: Human nature and the need for social connection. WW Norton \& Company, 2008.

[22] Pond, R. S., Joseph Brey, and C. Nathan DeWall. "Denying the need to belong: How social exclusion impairs human functioning and how people can protect against it." Psychology of loneliness (2011): 107-122.

[23] Sagan, O. \& Miller, E. D. (Eds.). Narratives of loneliness: Multidisciplinary perspectives from the 21st century. NY: Routledge, (2018).

[24] Shaver, Phillip, and Duane Buhrmester. "Loneliness, Sex-Role Orientation and Group Life: A Social Needs Perspective." Basic Group Processes (1983): 259-288. doi:10.1007/978-1-4612-5578-9_11.

[25] Heinrich, Liesl M., and Eleonora Gullone. "The Clinical Significance of Loneliness: A Literature Review.” Clinical Psychology Review 26, no. 6 (October 2006): 695-718. doi:10.1016/j.cpr.2006.04.002.

[26] Mcwhirter, Benedict T. "Loneliness: A Review of Current Literature, With Implications for Counseling and Research.” Journal of Counseling \& Development 68, no. 4 (March 4, 1990): 417-422. doi:10.1002/j.1556-6676.1990.tb02521.x.

[27] Booth, Richard, David Bartlett, and Joel Bohnsack. "An examination of the relationship between happiness, loneliness, and shyness in college students." Journal of College Student Development (1992).

[28] Hawkley, Louise C., Ronald A. Thisted, Christopher M. Masi, and John T. Cacioppo. "Loneliness predicts increased blood pressure: 5-year cross-lagged analyses in middle-aged and older adults." Psychology and aging 25, no. 1 (2010): 132-141.

[29] Riggio, Ronald E., Kristin P. Watring, and Barbara Throckmorton. "Social Skills, Social Support, and Psychosocial Adjustment." Personality and Individual Differences 15, no. 3 (September 1993): 275-280. doi:10.1016/0191-8869(93)90217-q.

[30] Shankar, Aparna, Anne McMunn, James Banks, and Andrew Steptoe. "Loneliness, Social Isolation, and Behavioral and Biological Health Indicators in Older Adults.” Health Psychology 30, no. 4 (2011): 377-385. doi:10.1037/a0022826. 
[31] Wilson, Robert S., Steven E. Arnold, Julie A. Schneider, Yan Li, and David A. Bennett. "Chronic Distress, Age-Related Neuropathology, and Late-Life Dementia." Psychosomatic Medicine 69, no. 1 (January 2007): 47-53. doi:10.1097/01.psy.0000250264.25017.21.

[32] Mellqvist Fässberg, Madeleine, Svante Östling, Arjan W. Braam, Kristoffer Bäckman, John R. M. Copeland, Manfred Fichter, Sirkka-Liisa Kivelä, et al. "Functional Disability and Death Wishes in Older Europeans: Results from the EURODEP Concerted Action." Social Psychiatry and Psychiatric Epidemiology 49, no. 9 (February 20, 2014): 1475-1482. doi:10.1007/s00127-0140840-1.

[33] Kennedy, Susan, Janice K. Kiecolt-Glaser, and Ronald Glaser. "Immunological Consequences of Acute and Chronic Stressors: Mediating Role of Interpersonal Relationships.” British Journal of Medical Psychology 61, no. 1 (March 1988): 77-85. doi:10.1111/j.2044-8341.1988.tb02766.x.

[34] Cacioppo, John T., Stephanie Cacioppo, John P. Capitanio, and Steven W. Cole. "The Neuroendocrinology of Social Isolation." Annual Review of Psychology 66, no. 1 (January 3, 2015): 733-767. doi:10.1146/annurev-psych-010814-015240.

[35] Brannon, L. \& Feist, J. "Health psychology: An introduction to behaviour and health." Toronto, Canada: Thomson Wadsworth, (2004).

[36] Yarnold, Paul R., Edward A. Michelson, David A. Thompson, and Stephen L. Adams. Journal of Behavioral Medicine 21, no. 6 (1998): 545-563. doi:10.1023/a:1018796628917.

[37] Rokach, Ami, and Brock Heather. "Loneliness: A multidimensional experience." Psychology: A Journal of Human Behavior (1997).

[38] Rokach, Ami, and Heather Brock. “Coping With Loneliness.” The Journal of Psychology 132, no. 1 (January 1998): $107-127$. doi:10.1080/00223989809599269.

[39] Rokach, Ami, Miguel C. Moya, Tricia Orzeck, and Francisca Exposito. "LONELINESS IN NORTH AMERICA AND SPAIN." Social Behavior and Personality: An International Journal 29, no. 5 (January 1, 2001): 477-489. doi:10.2224/sbp.2001.29.5.477.

[40] Rokach, Ami, and Monika Sharma. "The loneliness experience in a cultural context." Journal of Social Behavior and Personality 11, no. 4 (1996): 827.

[41] Bloom, Joan R., and David Spiegel. "The Relationship of Two Dimensions of Social Support to the Psychological Well-Being and Social Functioning of Women with Advanced Breast Cancer." Social Science \& Medicine 19, no. 8 (January 1984): 831837. doi:10.1016/0277-9536(84)90400-3.

[42] Sha'ked, Ami, and Ami Rokach. "Loss and Loneliness in Close Relationships." Psychology Journal 11, no. 1 (2014).

[43] Friedman, Gaby, Victor Florian, and Esther Zernitsky-Shurka. "The Experience of Loneliness Among Young Adult Cancer Patients.” Journal of Psychosocial Oncology 7, no. 3 (November 7, 1989): 1-15. doi:10.1300/j077v07n03_01.

[44] Vogel, D. L., Wester, S. R., Heesacker, M., \& Madon, S. “Confirming gender stereotypes: A social role perspective. Sex Roles”, 48, no. (11-12) (2003): 519-528. doi:10.1023/a:1023575212526.

[45] Danneel, Sofie, Marlies Maes, Janne Vanhalst, Patricia Bijttebier, and Luc Goossens. "Developmental Change in Loneliness and Attitudes Toward Aloneness in Adolescence." Journal of Youth and Adolescence 47, no. 1 (May 4, 2017 ): $148-161$. doi:10.1007/s10964-017-0685-5.

[46] Maté, Gabor. When the body says no: The cost of hidden stress. Vintage Canada, 2011.

[47] Cacioppo, John T., and Stephanie Cacioppo. "Social Relationships and Health: The Toxic Effects of Perceived Social Isolation." Social and Personality Psychology Compass 8, no. 2 (February 2014): 58-72. doi:10.1111/spc3.12087.

[48] Christ, Grace H., Karolynn Siegel, Barbara Freund, Deborah Langosch, Shelly Hendersen, Diane Sperber, and Lois Weinstein. “Impact of Parental Terminal Cancer on Latency-Age Children.” American Journal of Orthopsychiatry 63, no. 3 (1993): 417425. doi:10.1037/h0079451. 